\title{
PELATIHAN PEMBAWA ACARA KEGIATAN KEAGAMAAN BAGI REMAJA DAN IBU-IBU PENGAJIAN MASJID HIKMAH PEKANBARU
}

\author{
Desliana Dwita*, Jupendri, Jayus, Fitria Mayasari \\ Prodi Ilmu Komunikasi, Fakultas Ilmu Komunikasi UMRI \\ *email: deslianadwita@umri.ac.id
}

\begin{abstract}
Abstrak
Masjid Hikmah yang terletak di Jalan Melati gang Hikmah Kelurahan Sukajadi, Kecamatan Sukajadi Pekanbaru merupakan salah satu masjid yang memiliki Ikatan Remaja Masjid yang bernama REHIS (Remaja Masjid Hikmah dan Sekitarnya) dan perkumpulan ibu-ibu pengajian dengan nama Peswajiramah (Persatuan Wanita Jiran Masjid Hikmah). Remaja yang tergabung dalam REHIS biasanya menjadi pembawa acara dalam Santapan Rohani Ramadhan yang dilaksanakan sebelum sholat tarawih. Ibu-ibu di lingkungan Masjid Hikmah juga secara bergiliran menjadi pembawa acara wirid. Permasalahannya adalah bagaimana menjadi pembawa acara keagamaan yang terampil, memiliki pengetahuan agama, dan percaya diri? Untuk itu dilakukan kegiatan pengabdian kepada masyarakat yang bertujuan agar remaja Masjid Hikmah dan ibu-ibu pengajian Masjid Hikmah memiliki keterampilan, pengetahuan, dan kepercayaan diri untuk menjadi pembawa acara keagamaan. Materi yang disampaikan tentang public speaking, teknik menjadi pembawa acara kegiatan keagamaan, dan komunikasi dakwah. Metode yang dilakukan dengan ceramah, diskusi, tanya jawab dan praktik. Hasil kegiatan ini, remaja masjid dan ibu-ibu pengajian menjadi lebih mengerti tentang persiapan untuk menjadi seorang pembawa acara yang terampil dan komunikatif. Dengan bertambahnya pemahaman tentang pembawa acara, maka remaja dan ibu-ibu pengajian menjadi mampu dan percaya diri untuk menjadi pembawa acara dalam kegiatan keagamaan.
\end{abstract}

Kata kunci : Pembawa Acara, Kegiatan Keagamaan, Dakwah

\section{PENDAHULUAN}

Masjid Hikmah yang terletak di Jalan Melati gang Hikmah Kelurahan Sukajadi, Kecamatan Sukajadi Pekanbaru merupakan salah satu masjid yang memiliki Ikatan Remaja Masjid yang bernama REHIS (Remaja Masjid Hikmah dan Sekitarnya) dan ibu-ibu pengajian dengan nama Peswajiramah (Persatuan Wanita Jiran Masjid Hikmah).

Remaja yang tergabung dalam REHIS setiap bulan Ramadhan memiliki kegiatan rutin yaitu menjadi pembawa acara Santapan Rohani Ramadhan yang dilaksanakan sebelum sholat tarawih. Meskipun ada beberapa orang yang sudah mahir dan terampil menjadi pembawa acara, namun ada beberapa remaja yang masih malu, tidak percaya diri, dan tidak terampil dalam berkomunikasi khususnya menjadi pembawa acara kegiatan keagamaan.

Begitu pula dengan ibu-ibu Peswajiramah, kegiatan rutin yang dilaksanakan adalah pengajian setiap hari Kamis pukul 16.00-17.30 WIB. Dalam kegiatan pengajian ini, secara bergiliran ibu-ibu menjadi pembawa acara wirid. Ibu-ibu tersebut juga mengalami grogi, dan tidak percaya 
diri untuk menjadi pembawa acara kegiatan keagamaan.

Mengingat kegiatan yang dilakukan REHIS dan ibu-ibu Peswajiramah, maka dosen-dosen Program Studi Ilmu Komunikasi, Fakultas Ilmu Komunikasi Universitas Muhammadiyah Riau yang memiliki pengetahuan dan keterampilan di bidang komunikasi merasa perlu untuk mengadakan Pelatihan Pembawa Acara Keagamaan Bagi Remaja dan IbuIbu Pengajian Masjid Hikmah Pekanbaru.

Untuk menjadi pembawa acara yang juga merupakan penyampai pesan dalam sebuah kegiatan agar acara berjalan dengan baik, maka harus memiliki keterampilan menjadi seorang komunikator yang baik. Permasalahannya adalah bagaimana menjadi pembawa acara keagamaan yang terampil, memiliki pengetahuan agama, dan percaya diri.

Pengabdian ini dibatasi hanya pelatihan menjadi pembawa acara dalam kegiatan keagamaan saja, mengingat khalayak sasaran adalah remaja masjid dan ibu-ibu pengajian.

Tujuan kegiatan pengabdian ini adalah remaja dan ibu-ibu pengajian Masjid Hikmah memiliki keterampilan, pengetahuan, dan kepercayaan diri untuk menjadi pembawa acara keagamaan.

Harol D. Lasswell (Cangara, 1998:19) menjelaskan komunikasi pada dasarnya merupakan suatu proses yang menjelaskan siapa, mengatakan apa, dengan saluran apa, kepada siapa? Dengan akibat apa atau hasil apa? (Who?Says what? In which channel?To whom?With what effect?).

Mengutip Wikipedia, istilah pembawa acara ditujukan pada orang yang bertugas sebagai tuan rumah sekaligus pemimpin acara dalam panggung pertunjukan,hiburan,pernikahan dan acara-acara sejenis.

Terdapat beberapa kegiatan keagamaan, khususnya dalam agama Islam yang dilakukan untuk pembinaan keimanan dan ketaqwaan terhadap Tuhan yang Maha Esa. Kegiatan-kegiatan tersebut dapat berupa kegiatan harian, mingguan, bulanan, dan tahunan. Kegiatan keagamaan yang berupa kegiatan harian seperti shalat berjamaah dan berdoa. Kegiatan keagamaan yang bersifat mingguan seperti shalat Jumat berjamaah, contoh kegiatan bulananseperti kegiatan khusus bulan Ramadhan (buka puasa bersama, shalat tarawih,tadarus, ceramah Ramadhan. Sedangkan kegiatan tahunan seperti peringatan isra' mi'raj, peringatan maulid nabi SAW, peringatan Nuzulul Qur'an, dan lainnya.

\section{METODE PENGABDIAN}

Metode yang dilakukan dalam Pengabdian kepada Masyarakat ini adalah metode ceramah, diskusi, tanya jawab serta praktik. Diawali dengan pemberian materi tentang public speaking yang dilanjutkan dengan diskusi, tanya jawab, dan praktik. Begitu pula dengan materi Pembawa Acara Kegiatan Keagamaan dan materi Komunikasi Dakwah. Diawali dengan pemberian materi, diskusi, tanya jawab, dan praktik.

\section{HASIL DAN PEMBAHASAN}

Kegiatan pelatihan menjadi pembawa acara kegiatan keagamaan bagi remaja dan ibu-ibu pengajian di Masjid Hikmah Kecamatan Sukajadi 
Pekanbaru membuka wawasan bagi remaja dan ibu-ibu pengajian mengenai berbicara di depan umum, penampilan saat menjadi pembawa acara, terampil berkomunikasi, serta memiliki kepercayaan diri saat tampil di depan orang banyak.

Kegiatan dilakukan di Masjid Hikmah yang berada di Jalan Melati gang Hikmah, Kelurahan Sukajadi, Kecamatan Sukajadi Kota Pekanbaru. Peserta yang hadir terdiri dari Remaja Masjid Hikmah (REHIS) berusia antara 13-25 tahun, juga ibu-ibu pengajian (Peswajiramah) yang berusia antara 25-70 tahun.

Acara dilaksanakan pada hari Minggu tanggal 7 Mei 2017 mulai pukul 10.00 WIB hingga pukul 12.00 WIB. Pemateri terdiri dari Desliana Dwita, S.IP, M.I.Kom, Jupendri, S.Sos, M.I.Kom, dan Jayus, S.Sos, M.I.Kom. Sedangkan pembawa acara dilakukan oleh Fitria Mayasari, S.I.Kom, MA.

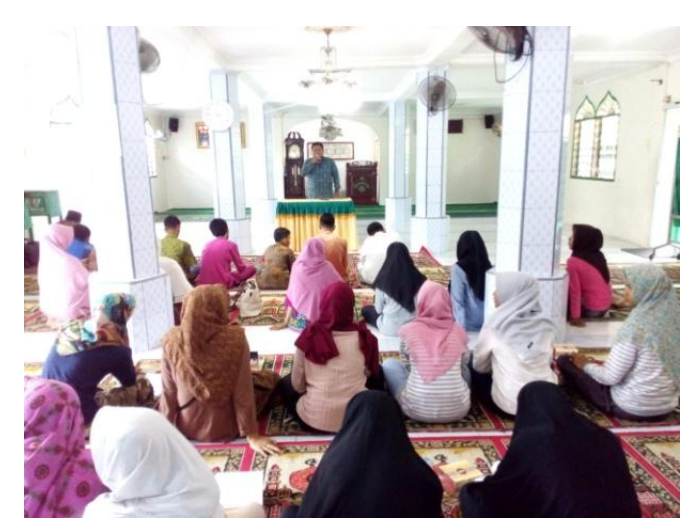

Gambar 4 Pemateri Memberikan Pelatihan

Menjadi pembawa acara merupakan bagian dari berbicara di depan umum. Terdapat beberapa isitilah untuk orang yang memandu sebuah acara yaitu pembawa acara, MC, atau protokol. Pembawa acara adalah orang yang membawakan acara atau memandu acara secara umum, terutama acara resmi, formal, atau seremonial yang terikat dengan etika protokoler. Pembawa acara resmi tidak dituntut berimprovisasi, tinggal membaca naskah yang sudah disiapkan oleh seksi acara dan harus menggunakan bahasa formal dan baku atau berbahasa Indonesia yang baik dan benar.

MC (Master of Ceremony) adalah orang yang membawa atau memandu jalannya acara tidak resmi (nonformal) dan semi-formal, seperti acara hiburan, pelatihan, seminar, workshop, dan sejenisnya. MC harus mampu berimprovisasi, humoris, menghibur audiens, membangkitkan semangat (antusiasme), mengenalkan pembicara, memimpin aplaus, dan kadang-kadang membawakan permainan (game) dan kuis di selasela acara.

Selanjutnya ada yang disebut protokol. Istilah protokol tidak merujuk pada manusia atau orang. Protokol bukan orang, tapi "sistem" atau "aturan". Kamus Besar Bahasa Indonesia (KBBI) mengartikannya sebagai: "peraturan upacara di istana kepala negara atau berkenaan dengan penyambutan tamu-tamu negara dsb.," dan "tata cara (upacara dsb) yang secara internasional berlaku dalam hubungan diplomatik". Menurut KBBI, protokol dalam bahasa percakapan sehari-hari merujuk pada "orang yang bertugas mengatur jalannya upacara".

Materi tentang menjadi Pembawa Acara Kegiatan Keagamaan yang disampaikan Jupendri, S.Sos, M.I.Kom. Materi tentang pembawa acara diikuti dengan antusias oleh peserta. Dijelaskan oleh pemateri bahwa membawakan acara dituntut berpenampilan yang baik karena penampilan adalah bagian dari 
komunikasi non verbal. Sebagai pembawa acara keagamaan seharusnya menggunakan busana muslim/ah rapi dan bersih. Hal ini akan memberikan kepercayaan diri seseorang ketika tampil di hadapan publik. Pakaian dalam ilmu komunikasi merupakan pesan non verbal. Pesan non verbal adalah pesan yang menggunakan isyarat atau gerakan tubuh untuk menyampaikan maksud dan tujuan oleh komunikator kepada komunikan.

Dalam suatu hasil penelitian yang dilakukan Albert Mahrabian (1971) bahwa tingkat kepercayaan dari komunikasi manusia meliputi $7 \%$ berasal dari pesan verbal dan 93\% dari pesan non verbal. Pesan non verbal yang dimaksud meliputi vokal suara sebesar $38 \%$ dan ekspresi muka sebesar 55\%. (Cangara, 2012:113)

Bahasa yang digunakan seseorang pada kegiatan keagamaan seperti Santapan Rohani Ramadhan harus menggunakan kalimat keagamaan. Dalam ilmu komunikasi, bahasa yang disampaikan seseorang merupakan pesan verbal.

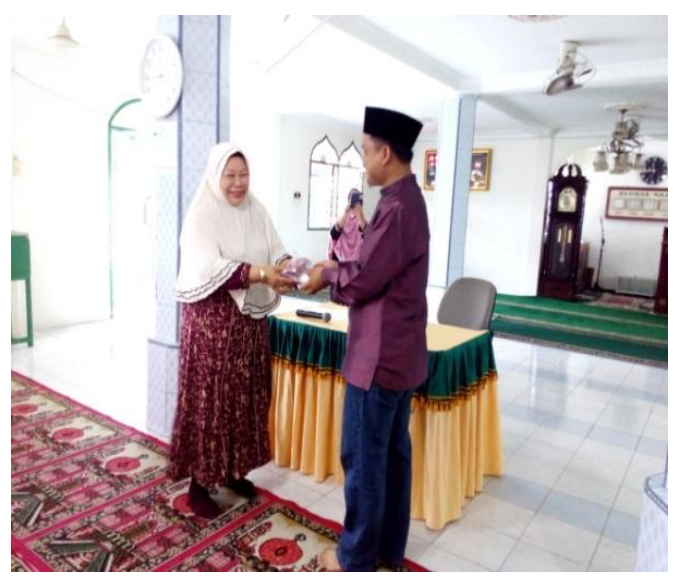

Gambar 5 Penyerahan kenang-kenangan kepada peserta aktif

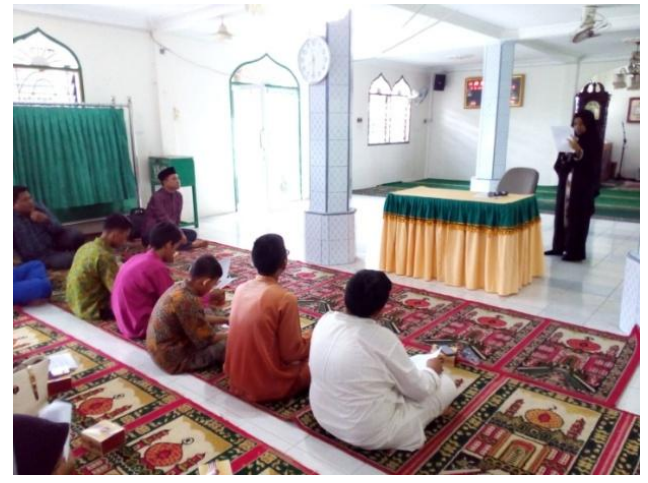

Gambar 3: Salah seorang peserta mempraktikan menjadi Pembawa Acara

Komunikasi menurut Carl I. Hovland (dalam Efendi, 2001:10) merupakan cara yang berurutan dalam merumuskan sebuah penyampaian informasi serta membentuk sikap dan sebuah pendapat. Dari definisi yang dikemukakan oleh Hovland, proses yang dilakukan seseorang (komunikator) dalam menyampaikan sebuah informasi kepada orang lain (komunikan) untuk mengubah perilaku komunikan atau pendapat. Dakwah secara arti bahasa (Saputra, 2011:1) yaitu panggilan, seruan ataupun ajakan, bentuk pengucapan tersebut dalam bahasa Arab disebut mashdar, sedangkan bentuk kata kerja (fi'il) nya bearti memanggil, menyeru atau mengajak (Da'a, Yad'u, Da'watan).

Dakwah menurut Hamka dakwah yaitu ajakan panggilan untuk menganut suatu pendirian yang ada dasarnya berkonotasi positif dengan substansi terletak pada aktivitas yang memerintahkan amar ma'ruf dan nahi mungkar (Saputra, 2011:1)

Dari definisi yang dijelaskan oleh Hamka tersebut, dapatlah ditarik kesimpulan, mengajak umat dalam berbuat kebaikan, mengenalkan Ketuhanan, membimbing kepada jalan yang lurus, mengajarkan untuk 
amar makruf dan nahi munkar, demi kemaslahatan dunia dan akhirat.

Dari definisi komunikasi dan dakwah tersebut maka istilah komunikasi dakwah merupakan ajakan yang dilakukan oleh komunikator dakwah dalam hal ini da'i, untuk mengajak komunikan dakwah dalam hal ini jamaahnya, dengan cara komunikasi verbal maupun non verbal, bertujuan kebaikan dunia dan akhirat.

Setelah materi disampaikan kemudian diadakan tanya jawab dengan peserta serta praktik hafalan surat yang ada dalam Al Qur'an. Salah seorang peserta membacakan surat An-Naba' yang merupakan salah satu surat yang telah dihafalnya.

\section{SIMPULAN}

Menjadi pembawa acara membutuhkan keterampilan, pengetahuan dan kepercayaan diri. Kepercayaan diri bisa terbentuk dengan adanya keberanian dan keyakinan, keterampilan diperoleh dengan banyak berlatih, pengetahuan didapat dengan banyak membaca.

Menjadi pembawa acara keagamaan dibutuhkan keterampilan berkomunikasi, pengetahuan tentang keagamaan, dan kepercayaan diri. Penampilan merupakan bahasa non verbal dalam komunikasi. Doa dan ucapan salam dalam bahasa Arab merupakan keharusan dalam membawakan acara keagamaan.

Strategi komunikasi dalam berdakwah perlu diketahui untuk menarik atau mengajak pendengar mengikuti apa yang disampaikan oleh pendakwah. Komunikasi dakwah disampaikan sebagai upaya persuasi, mengajak komunikan menuju kebaikan dunia dan akhirat.
Remaja masjid dan ibu-ibu pengajian yang kerap melakukan kegiatan keagamaan harus mengetahui dan melatih diri menjadi pembawa acara dalam kegiatankegiatan yang dilaksanakan di masjid yang berada di lingkungannya. Remaja Masjid Hikmah dan Persatuan Wanita Jiran Masjid Hikmah yang berada di Jalan Melati Kecamatan Sukajadi Kota Pekanbaru telah mendapatkan pengetahuan untuk menjadi pembawa acara yang terampil dalam kegiatan keagamaan.

\section{UCAPAN TERIMAKASIH}

Ucapan terima kasih disampaikan kepada:

1. Lembaga Penelitian dan Pengabdian Masyarakat (LPPM ) Universitas Muhammadiyah Riau (UMRI) yang telah memberikan dukungan berupa biaya dan motivasi.

2. Fakultas Ilmu Komunikasi Universitas Muhammadiyah Riau yang telah memberi dukungan agar terselenggaranya kegiatan pengabdian kepada masyarakat ini.

3. Ketua Peswajiramah Pekanbaru, Hj.Umma Hani, S.Pd yang telah menerima dan menyambut dengan baik tim pengabdian kepada masyarakat dari Prodi Ilmu Komunikasi UMRI.

4. Ibu Hj.Suwarna Nazir yang telah memfasilitasi dan menyiapkan peserta dan tempat untuk pelaksanaan pengabdian kepada masyarakat ini.

5. Seluruh peserta pelatihan, yaitu remaja masjid Hikmah (REHIS) dan ibu-ibu pengajian Masjid Hikmah (Peswajiramah) Kelurahan Sukajadi, Kecamatan Sukajadi, Kota Pekanbaru yang 
begitu antusias dalam mengikuti kegiatan ini.

\section{DAFTAR PUSTAKA}

[1] Badan Pusat Statistik Kota Pekanbaru. 2016. Kecamatan Sukajadi Dalam Angka. Pekanbaru: BPS Kota Pekanbaru

[2] Cangara, Hafied. 2012. Pengantar Ilmu Komunikasi (Edisi 2). Jakarta: Rajawali Pers

[3] Effendy, Onong Uchjana. 2008. Ilmu Komunikasi, Teori \& Praktik. Bandung : PT. Remaja Rosdakarya.

[4] Laskowsi, Lenny. 2001. 10 Days to More Confident Public Speaking. USA: Warner Books

[5] McPheat, Sean. 2010. Effective Comunication Skills. Swedia:MTD Training \& Ventus Publishing

[6] Santrock, J.W.1999. Life Span Development ( terjemahan ). Boston: Mc Graw Hill
[7] Saputra, Wahidin. 2011. Pengantar Ilmu Dakwah. Jakarta: PT. RajaGrafindo Persada 